Treatment of calcium and pigment stones

No effective method yet exists for dissolving calcium gall stones or those composed primarily of brown or black pigment. Glyceryl mono-octanoate, Palmidrol, Pluronic F-68, and bile salts may all contribute to the disruption of the organic matrix and may be infused via a catheter placed in the biliary tree. Successes are few and side effects such as nausea and diarrhoea occur in up to $40 \%$ of patients, comparable with the incidence of side effects to mono-octanoin. Other agents that have been used include methylhexyl ether and ureaEDTA (ethylenediaminetetra-acetic acid) solutions, but the problems with these treatments are that the solutions are not readily available, the regimens are complicated, and experience is limited at present to only one or two centres. It is too early to say whether such forms of treatment will replace conventional endoscopic sphincterotomy or operation on the common bile duct.

\section{Conclusion}

Cholecystectomy presently remains the best option for a patient with stones in the gall bladder. In good hands the operation is safe, effective, and if properly indicated is associated with very few postoperative problems. Under certain circumstances litholysis with bile acids may be offered as an alternative. Extracorporeal lithotripsy, though attractive, is expensive and to some extent experimental. More experience of this technique is needed to ensure that it is safe in the long term. Non-operative management of stones in the gall bladder requires surveillance after dissolution, and further treatment may be required if stones recur. Many patients will therefore feel that the best option remains cholecystectomy unless an operation is contraindicated for a medical reason.

Choledocholithiasis is best managed in the first instance by endoscopic sphincterotomy, at least in older patients or those in whom an operation is contraindicated. Sphincterotomy alone may be sufficient, but mechanical extraction of the stones mav be necessary. In certain circumstances infusion of a litholytic agent may be required to dissolve a stone or fragments of a stone; extracorporeal shock wave lithotripsy may also be used. No effective drug treatment is available for stones composed primarily of calcium or bile pigment, which are either removed by operation or, when present in the common bile duct, by endoscopic sphincterotomy. Mechanical procedures can enhance the removal of a stone that does not pass spontaneously.

The variety of procedures now available to clinicians for managing stones in the biliary tract has increased greatly the range of options when deciding what treatment to offer patients. Treatment has to be tailored to each patient and will depend on the site and nature of the gall stones, the age of the patient, and the presence of any associated diseases that might add a risk to anaesthesia and operating.

\section{Bibliography}

Bouchier IAD. Non-surgical treatment of gall stones; many contenders but who will win the crown? Gut 1988;29:137-42

Cotton PB. Endoscopic management of bile duct stones; (apples and oranges). ( $\mathrm{ju}$ $1984 ; 25: 587-97$.

Fromm H. Gall stone dissolution therapy. (jastroenterology 1986;91:1560-7.

Neoptolemos JP, Hofmann AF, Moossa AR. Chemical treatment of stones in the biliary tree. Br $\mathcal{J}$ Surg 1986;73:515-24.

ackmann $M$, Delius $M$, Sauerbruch $T$, $e t$ al. Shockwave lithotripsy of gall bladder stones. N Engl f Med 1988:318:391-7.

Tint GS, Salen G, Shefer S. Effect of ursodeoxycholic acid and chenodeoxycholic acid on cholesterol and bile acid metabolism. Gastroenterology 1986;91:100718.

\title{
Toddlers, teapots, and kettles: beware intraoral scalds
}

\author{
D J Dye, M A P Milling, E R Emmanuel, K V Craddock
}

\section{The possibility of intraoral damage, which is potentially lethal, must be considered in all cases of scalds around the mouth; when it occurs observation in an intensive care unit is recommended}

Welsh Burns and Plastic Surgery Unit, St Lawrence Hospital, Chepstow, Gwent

D J Dye, FCANAES, consultant anaesthetist

M A P Milling, FRCS, consultant plastic surgeon

E R Emmanuel, FFARACS, consultant anaesthetist

K V Craddock, FCANAES, consultant anaesthetist

Correspondence to: Dr Dye.

$\operatorname{Br}$.Med $\mathcal{Y} 1990 ; 300: 597-8$
The association of teapots and surface scalds in small children is well known. Damage inside the mouth and pharynx is potentially lethal yet not always recognised. A recent report highlighted the dangers: a 1 year old girl suffered brain damage as a result of obstruction of her upper airway after a delay in transferring her to hospital after she had received intraoral scalds from a teapot spout.' This case occurred nine years ago and has only just been settled in court.

Two cases recently referred to this regional burns unit illustrate the dangers and the need for doctors in general practice and accident and emergency departments to be aware of the potential problems in children with facial scalds

\section{Case reports}

CASE 1

A 2 year old infant applied a teapot spout to her lips and suffered superficial and deep dermal scalds to the lips, chin, and chest totalling about $1.5 \%$ of her body surface area. She was taken to a local hospital, where it proved impossible to examine the inside of her mouth. She did not have respiratory distress but was kept in the intensive care unit for observation. During the night (some eight hours after the scald) she developed inspiratory stridor and had difficulty in swallowing. A

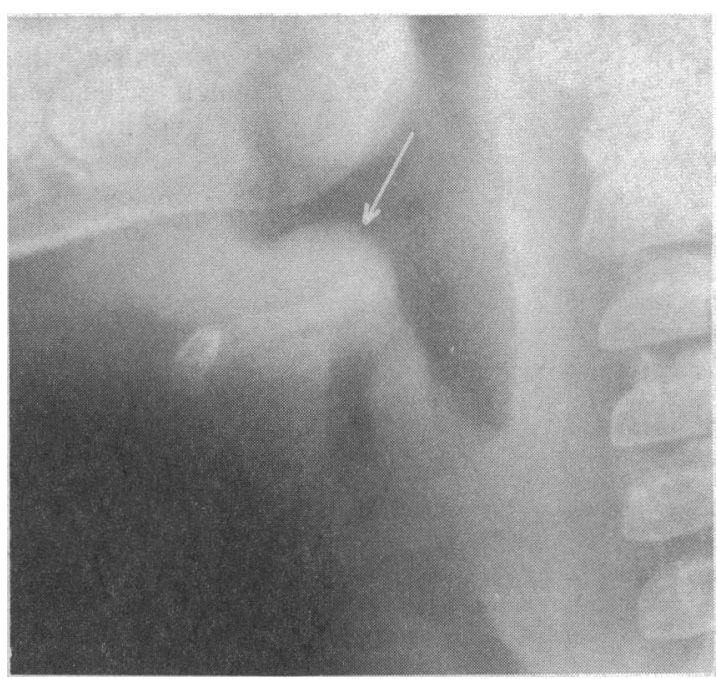

FIG 1-Swollen epiglottis (arrowed) secondary to ingestion of hot water (case 1)

difference of opinion arose about the need to support her airway, although a lateral neck $x$ ray film showed an epiglottis the size of a ripe cherry (fig 1). The decision was made not to intubate the trachea but to continue to observe the child in the intensive care unit. 
The next morning the child was transferred to this unit with an anaesthetist in attendance. On arrival, after a journey of three hours, her oxygen saturation when she was breathing air was $90 \%$ (Ohmeda pulse oximeter). The respiratory rate was $40 / \mathrm{min}$ with slight inspiratory stridor. Air entry on the left side of the chest was diminished, and a chest $x$ ray film showed widespread consolidation in the left lung. On examination under general anaesthesia the epiglottis was reported to be almost normal, but subglottic oedema limited the size of endotracheal tube to $3 \mathrm{~mm}$ diameter $(4.5 \mathrm{~mm}$ predicted). Copious purulent secretions were aspirated from the trachea, and considerable retention of sputum had evidently occurred overnight and during transfer. The child was allowed to recover from the anaesthetic and was sedated to improve tolerance of the oral endotracheal tube. A course of amoxycillin was started.

A further examination under anaesthesia 24 hours later showed an epiglottis almost normal in form but covered with sloughed mucosa, as was most of the lining of the mouth and pharynx. A chest $x$ ray film showed that the consolidation previously seen had resolved. The child subsequently made a full recovery.

CASE 2

A 3 year old boy was ieferred to this unit with scalds over $40 \%$ of his body surface area including his face, neck, and chest, which he had sustained when he pulled the flex of an electric kettle. There was no suggestion that he had ingested any hot water. On his arrival some 40 minutes after the scalding the child's airway required urgent support because of incipient obstruction of the upper airway. Intraoral scalding seemed to have been caused by near boiling water cascading into the child's open mouth.

Examination under anaesthesia showed severe mucosal cedema in the pharynx and over the epiglottis with some sioughing of the mucosa. Suppori of the airway with an endotracheal tube was required for six days, at the end of which most of the epiglottis had separated as a slough.

Surprisingly, near complete recovery foilowed with no apparent prob'ems in swallowing or phonation and only slight stridor on forced inspiration.

\section{Discussion}

The radiographic appearance of the epiglottis in case 1 (fig 1) was similar to that seen in acute epiglottitis (fig 2 ); although the degree of swelling of the base of the epiglortis and its supporting tissue is likely to be grearcr in bacterial epiglottitis, a greatly enlarged epigiotis from any cause is an alarming sign. The child in cess: 1 probably cante close to having total obstruc-

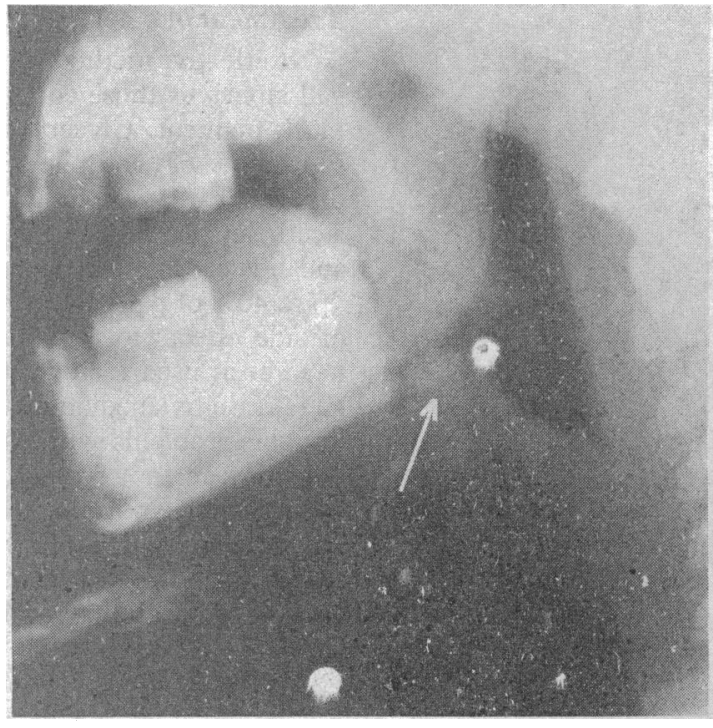

FIG 2-Acute bacterial epiglottitis (epiglottis arrozved)

tion of her upper airway during the night after her admission. The child in case 2 would probably not ${ }^{2}$ ave survived a longer transfer between hospitals.

In all cases of scalds - and chemical burns - around the mouth the possibility of intraoral damage must be considered. The child should be transferred with a suitable medical escort (usually an experienced anaesthetist) to a unit where intensive care and support for the airway are available. If there are signs of obstruction of the upper airway the airway should be secured before transfer. Conservative management in doubtful cases should be in an intensive care unit where immediate medical attention is available. Signs of epiglottic swelling (drooling saliva, difficulty in swallowing, or inspiratory stridor) are an indication for examination under inhalation anaesthesia by an experienced anaesthetist, and endotracheal intubation is likely to be required. Facilities for immediate tracheostomy or cricothyroid jet ventilation, or both, must be available. In acute epiglottitis attempts to visualise the epiglottis by using a tongue depressor commonly provoke complete respiratory obstruction and should probably be avoided in cases of intraoral scalding. If obstruction occurs and endotracheal intubation proves impossible immediate cricothyroid puncture and jet ventilation or minitracheostomy will be required.

1 Prentice T. $\$ 535000$ damages after GPs' negligence. The Times 1989 April 15: 3 (coil).

Brahams D. Respiratory failure in a young child after aspiration of hot tea. Anaesthesia 1989;44:858-9.

(Accept:d 17 November 1989)

\section{ANY QUESTIONS}

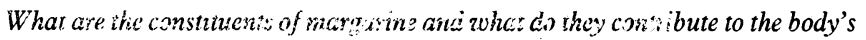
nutritional requirements?

Margarines are produced by blending a mixture of oils and fats with the appropriate emulsifying agents. The yriginal process developed in the $1860 \mathrm{~s}$ hy $\mathrm{H}$ Mège Mouriès used becf for, bu present rlay margarines rely on plant fats and oils for their major ingredients. an aren of the oils are partially hydrogenated to give the unixtu: an anowntaic melting poinc. Soft margarines contain a higher proportins of winydrogenated oils, but waly those prepared from oils that contain high levels of cis:cis linoleic acid (sunflower, safflower, and maize oils) are rich source: of polyunsaturated fats. Traditional margarines contain $81-82 \%$ fat and so are similar to butter as sources of fat and energy. In addition to fat, margarines contain small amounts of protein, often from milk, to help emulsification, and salt is added to flavour the mixture, which alsc has flavourings to simulate the iaste of butter. In the United Kingdom and many other countries the margarines are fortified with added vitamins $A$ and $D$ so that in this respect they are equivalent to butter. ${ }^{2}$ At present margarine consumption contributes about $6 \%$ of total energy intake, about $13 \%$ of total fat intake, $10 \%$ of vitamin A intake, and over $40 \%$ of vitamin $D$ intake. ${ }^{3}$ The polyunsaturated margarines are major contributors to the intake of polyunsaturated fats. -D A T SOUTHGATE, nead, nutrition and food quality department, Agricultural and Food Research Council's Institute of Food Research, Norwich

3̂tuyvenberg JH van, ed. Margarine: an economic, social and scientific history 1869-1969. Liverpool: Liverpool University Press, 1969.

2 Paul AA, Southgate DAT. McCance and Widdowson's the composition of foods. 4th ed. London: HMSO, 1978 .

3 Ministry of Agriculture, Fisheries, and Food. Household consumption and expenditure, 1987. Londion: HMSO, 1989 